\title{
Measurement of changes in perfusion after carotid endarterectomy by 3D pseudo-continuous arterial spin labeling
}

\section{Dongsheng Kong}

Chinese PLA General Hospital

\section{Zhe Xue}

Chinese PLA General Hospital

\section{Chen Wu}

Chinese PLA General Hospital

\section{Wenxin Wang}

Chinese PLA General Hospital

\section{Zhenghui Sun}

Chinese PLA General Hospital

Xinguang YU ( $\nabla$ xinguang_yu301@163.com )

Chinese PLA General Hospital https://orcid.org/0000-0001-6898-3996

\section{Research article}

Keywords: perfusion, carotid endarterectomy, pseudo-continuous arterial spin labeling, carotid stenosis

Posted Date: March 27th, 2020

DOI: https://doi.org/10.21203/rs.3.rs-19545/v1

License: (c) (i) This work is licensed under a Creative Commons Attribution 4.0 International License. Read Full License 


\section{Abstract}

Background:Carotid endarterectomy (CEA) is an effective method for treating cerebral ischemia caused by carotid stenosis, but there may be a risk of perfusion pressure breakthrough during early perfusion recovery. As a non-invasive and contrast-free magnetic resonance examination method, arterial spin labeling can be used for continuous observation and measurement in the early postoperative period of carotid endarterectomy.

Results: Nineteen patients with severe unilateral carotid stenosis were examined using 3D pseudo-continuous arterial spin labeling before and after CEA, and we found that the pattern of dynamic cerebral blood flow changes is not the same in different regions.

Conclusions: 3D pseudo-continuous arterial spin labeling might be helpful for the improvement of postoperative treatment and care of severe unilateral carotid stenosis patients.

\section{Background}

Ischemic stroke is closely associated with carotid atherosclerotic stenosis. Approximately $20-30 \%$ of transient ischemic attacks or cerebral infarctions are caused by severe carotid stenosis or occlusion[1]. Severe carotid stenosis decreases the blood vessel cross-sectional area and increases the local blood flow velocity. However, the blood flow per unit time is reduced[2], which is reflected by lower cerebral blood flow (CBF) in the brain. Carotid endarterectomy (CEA) is an effective mode for treating carotid stenosis and it has been clinically proven to significantly improve the intracranial CBF and effectively resolve the patient's clinical symptoms. However, CEA can cause iatrogenic complications such as perioperative stroke[3]. In particular, postoperative hyperperfusion syndrome has attracted increasing attention from clinicians due to the difficulty in its prediction and its serious consequences $[4,5]$. Therefore, monitoring the time and severity of postoperative hyperperfusion is of significance for both objective analysis of surgical efficacy and to prevent postoperative hyperperfusion syndrome[6-8].

Conventional vascular imaging techniques such as computed tomography arthrography (CTA), magnetic resonance angiography, and digital subtraction angiography (DSA) often overestimate the degree of arterial stenosis due to the presence of vascular remodeling[5]. The use of CT perfusion imaging or single-photon emission computed tomography to measure intracranial blood perfusion is also limited in clinical practice due to the presence of radioactivity[9-11]. In recent years, magnetic resonance perfusion imaging techniques such as dynamic susceptibility contrast (DSC) and arterial spin labeling (ASL) have received much attention owing to their good tissue resolution and lack of radioactivity. With the continuous advancement and updates of ASL in recent years, the measurement of perfusion has evolved from qualitative to quantitative. Compared with DSC, which requires a bolus injection of paramagnetic contrast agents, ASL is non-invasive and does not need contrast agents and therefore has a broader target population and development prospect. The specificity and sensitivity of diagnosis by ASL meet clinical requirements, and its application in patients with carotid atherosclerosis is expanding[12,13]. Previous studies have pointed out that for the changes of overall perfusion after CEA[6]. After checking the perfusion of different parts, we found that some corrections 
were needed for the time of prediction. In this study, we used ASL to evaluate the continuous change in cerebral perfusion during the early post-CEA period.

\section{Results}

\section{Medical history}

Medical history revealed that 11 patients had previous hypertension, 7 had previous diabetes, 16 had previous hyperlipidemia, and 12 were smokers. Preoperative symptoms included numbness of the limbs (17 patients), dizziness (11 patients), decreased visual acuity (4 patients), and amaurosis (6 patients). Details are shown in Table 1.

Table 1

Baseline characteristics

\begin{tabular}{|ll|}
\hline characteristics & $\mathbf{n}$ \\
\hline Age, median (range) & $63.57(46-79)$ \\
\hline Sex & \\
\hline Female & $7(36.8 \%)$ \\
\hline Male & $12(63.2 \%)$ \\
\hline Sides & \\
\hline Right & $5(26.3 \%)$ \\
\hline Left & $14(73.7 \%)$ \\
\hline Risk factors & \\
\hline Hypertension & 11 \\
\hline Diabetes & 7 \\
\hline Hyperlipidemia & 16 \\
\hline Smoking & 12 \\
\hline Symptoms, $n$ (\%) & \\
\hline Limb numbness & 17 \\
\hline Dizziness & 11 \\
\hline Vision lost & 4 \\
\hline
\end{tabular}

\section{CBF values in different regions}

The CBF values of the bilateral frontal lobe, temporal lobe, watershed area, and basal ganglia were increased after CEA $(\mathrm{D}<0.01)$. which are shown in Table 2. There was a significant difference in CBF between the Loading [MathJax]/jax/output/CommonHTML/jax.js 
stenotic and contralateral frontal lobes before CEA $(p=0.012)$, but the difference in CBF between the stenotic and contralateral frontal lobes was not significant on days $1,2,3$, and 4 and at 3 months post-CEA $(p>0.05)$. The CBF differed significantly between the stenotic and contralateral temporal lobes before CEA $(p=0.010)$ and at 3 months post-CEA $(p<0.05)$, but not on days $1,2,3$, and 4 post-CEA $(p>0.05)$. Similarly, the CBF differed significantly between the ipsilateral side and the contralateral side of the watershed area before CEA $(p \leq 0.05)$ and at 3 months post-CEA $(p=0.001)$, but not on days 1,2 , and 4 post-CEA $(p>0.05)$. There were no significant differences in $C B F$ values between the two sides of the basal ganglia on the preoperative day and on days $1,2,3$, and 4 and at 3 months post-CEA $(p>0.05)$.

Table 2

Mean value and standard deviation of pre- and postoperative CBF

\begin{tabular}{|c|c|c|c|c|c|c|c|c|}
\hline & Frontal0 & Frontal1 & Temp0 & Temp1 & Watershed0 & Watershed1 & Basal0 & Basal1 \\
\hline TO & $\begin{array}{l}44.932 \pm \\
9.95\end{array}$ & $\begin{array}{l}49.911 \pm \\
9.771\end{array}$ & $\begin{array}{l}42.022 \pm \\
10.023\end{array}$ & $\begin{array}{l}50.752 \pm \\
9.01\end{array}$ & $\begin{array}{l}30.179 \pm \\
5.211\end{array}$ & $\begin{array}{l}33.516 \pm \\
4.307\end{array}$ & $\begin{array}{l}43.751 \pm \\
7.52\end{array}$ & $\begin{array}{l}45.681 \pm \\
7.006\end{array}$ \\
\hline T1 & $\begin{array}{l}55.834 \pm \\
14.299\end{array}$ & $\begin{array}{l}59.053 \pm \\
10.763\end{array}$ & $\begin{array}{l}55.954 \pm \\
14.622\end{array}$ & $\begin{array}{l}58.431 \pm \\
9.506\end{array}$ & $\begin{array}{l}35.254 \pm \\
4.498\end{array}$ & $\begin{array}{l}33.012 \pm \\
4.051\end{array}$ & $\begin{array}{l}51.817 \pm \\
10.209\end{array}$ & $\begin{array}{l}54.121 \pm \\
6.883\end{array}$ \\
\hline T2 & $\begin{array}{l}58.418 \pm \\
17.151\end{array}$ & $\begin{array}{l}60.027 \pm \\
13.112\end{array}$ & $\begin{array}{l}58.821 \pm \\
18.542\end{array}$ & $\begin{array}{l}60.043 \pm \\
10.58\end{array}$ & $\begin{array}{l}39.229 \pm \\
8.393\end{array}$ & $\begin{array}{l}48.478 \pm \\
16.809\end{array}$ & $\begin{array}{l}56.189 \pm \\
8.393\end{array}$ & $\begin{array}{l}56.374 \pm \\
6.653\end{array}$ \\
\hline T3 & $\begin{array}{l}60.741 \pm \\
16.059\end{array}$ & $\begin{array}{l}65.645 \pm \\
12.875\end{array}$ & $\begin{array}{l}57.410 \pm \\
17.24\end{array}$ & $\begin{array}{l}64.363 \pm \\
9.676\end{array}$ & $\begin{array}{l}33.831 \pm \\
2.645\end{array}$ & $\begin{array}{l}47.205 \pm \\
14.55\end{array}$ & $\begin{array}{l}54.091 \pm \\
11.544\end{array}$ & $\begin{array}{l}54.846 \pm \\
4.959\end{array}$ \\
\hline $\mathrm{T} 4$ & $\begin{array}{l}54.698 \pm \\
10.821\end{array}$ & $\begin{array}{l}60.337 \pm \\
8.376\end{array}$ & $\begin{array}{l}56.477 \pm \\
12.502\end{array}$ & $\begin{array}{l}61.860 \pm \\
0.694\end{array}$ & $\begin{array}{l}32.984 \pm \\
2.456\end{array}$ & $\begin{array}{l}37.558 \pm \\
14.233\end{array}$ & $\begin{array}{l}47.091 \pm \\
7.968\end{array}$ & $\begin{array}{l}47.278 \pm \\
5.563\end{array}$ \\
\hline T3M & $\begin{array}{l}53.449 \pm \\
3.82\end{array}$ & $\begin{array}{l}55.676 \pm \\
3.47\end{array}$ & $\begin{array}{l}53.001 \pm \\
2.168\end{array}$ & $\begin{array}{l}56.172 \pm \\
2.223\end{array}$ & $\begin{array}{l}35.506 \pm \\
4.329\end{array}$ & $\begin{array}{l}35.249 \pm \\
9.461\end{array}$ & $\begin{array}{l}47.881 \pm \\
3.694\end{array}$ & $\begin{array}{l}46.540 \pm \\
1.893\end{array}$ \\
\hline$P$ & 0.068 & 0.018 & 0.015 & 0.002 & 0.003 & 0.067 & 0.007 & 0.000 \\
\hline \multicolumn{9}{|c|}{ 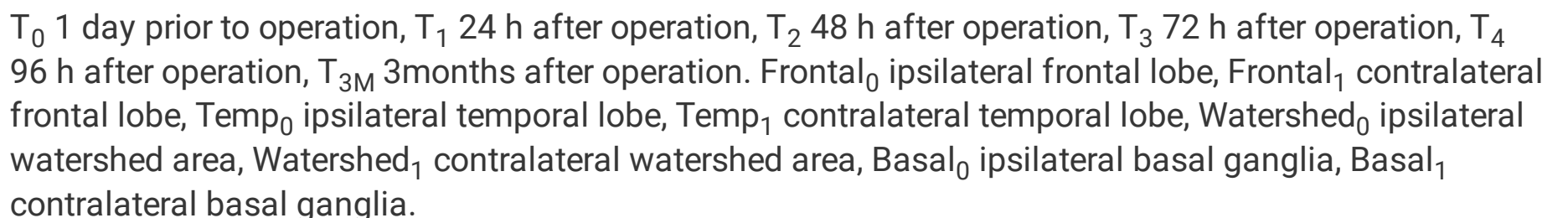 } \\
\hline
\end{tabular}

The increases in CBF values of the ipsilateral side: frontal lobe (35\%), temporal lobe (40\%), watershed area $(30 \%)$, basal ganglia (28\%); the contralateral side: frontal lobe (32\%), temporal lobe $(27 \%)$, watershed area (45\%), basal ganglia(23\%). The data are shown in Fig. 2.

\section{Pattern of dynamic cerebral blood flow}

In the early postoperative period, the CBF values of the frontal lobe and temporal lobe reached the peak on the ipsilateral side at $72 \mathrm{~h}$ after CEA, then declined at $96 \mathrm{~h}$, and remained relatively stable at 3 months; the $\mathrm{CBF}$ values of the watershed area and basal ganglia in most patients reached the peak on the ipsilateral side f $10 \mathrm{~h}$ aftar $\mathrm{C} C \Lambda$ donmannd at $72 \mathrm{~h}$ and ramained relatively stable thereafter. CBF values of the contralateral Loading [MathJax]/jax/output/CommonHTML/jax.js 
side, showed a similar trend to the ipsilateral side, but the increase in CBF on the contralateral side was smaller than that on the ipsilateral side. The data are illustrated in Fig. 3.

\section{Discussion}

Intracranial blood is supplied by bilateral arteries interlinked by communicating arteries. The areas supplied by the internal carotid artery include the frontotemporal cortex, basal ganglia, and watershed area. When internal carotid stenosis occurs, self-regulation of blood flow and dilation of blood vessels decrease the cerebral perfusion pressure. However, the CBF in the frontal and temporal lobes is maintained at a normal level during the early stage of stenosis due to the rich vascular network and collateral circulation between the anterior cerebral artery and the middle cerebral artery[14]. The CBF decreases only when the perfusion pressure in these areas drops below a certain threshold and is beyond the control of self-regulation. Although intracranial perfusion has already decreased markedly at this time, no obvious infarction can be detected by MRI. As intracranial perfusion continues to decrease, neuronal cells will undergo irreversible damage[15]. To avoid these serious consequences, early CBF monitoring should be performed on areas that are sensitive to ischemia and hypoxia.

When internal carotid plaque is removed, self-regulation of blood flow and dilation of blood vessels restore blood flow in the arterial lumen, recover intracranial blood supply and increase the cerebral perfusion pressure. Therefore, the efficacy of CEA should be evaluated on the basis of postoperative hemodynamics and cerebral perfusion recovery[16]. Our study confirmed that CEA significantly improved the severe preoperative reduction in intracranial perfusion. The CBF was increased to varying degrees after CEA on both the ipsilateral and contralateral sides, and the increase was greater on the ipsilateral sides of the watershed area and basal ganglia.

Although CEA is effective in treating carotid stenosis and can significantly improve CBF in patients, the possibility of a significant pathological increase in postoperative perfusion should not be overlooked. A previous study reported that patients who underwent CEA had a 16-30\% chance of developing cerebral hyperperfusion syndrome (CHS) when the CBF increased by more than twofold[17]. Brain hemorrhage and swelling were more likely to occur during this time, and complications such as cerebral hemorrhage, epilepsy, delirium, coma, and headache can also develop when there is severe stenosis or poor collateral circulation[18]. In the past we focused on global intracranial perfusion, which is correct but can go further. According to the results, the CBF values of the frontal and temporal lobes peaked at $72 \mathrm{~h}$, while those of the watershed area and the basal ganglia peaked at $48 \mathrm{~h}$ postoperatively; then all gradually decreased to a stable level. This may be because after completion of CEA and recanalization, although there is abundant blood flow in the brain, the distribution of blood circulation is uneven, and CEA impairs baroreflex and attenuates vascular self-regulation, leading to a failure of intracranial arterioles to adapt to hyperperfusion promptly[1921]. Meanwhile, due to their marginal position among the arteries and the lower number of vascular branching/anastomosis, the watershed area and the basal ganglia have abnormal perfusion, which causes cerebral hemorrhage. Considering that cerebral hemorrhage often occurs in the ischemic area, the watershed area might be focused on to prevent subsequent severe complications. 
This study has several limitations: (1) As this is a single-center study, it is prone to selection bias; (2) As the subjects were elderly patients with severe carotid stenosis and the CBF values measured by ASL decreases with age, these subjects do not fully represent the entire patient population; (3) Compared with 3D voxel analysis, subjective factors are inevitable when hand-drawing the ROI for the analysis of cerebral perfusion images; (4) only a single PLD of $2.0 \mathrm{~s}$ as recommended was used in this study, which might lead to inaccurate blood flow measurement.

\section{Conclusion}

The pattern of dynamic CBF changes is not the same in different regions, which may be helpful for the improvement of postoperative treatment and care.

\section{Methods}

\section{Patient information}

This study included 19 symptomatic patients with severe unilateral carotid stenosis who were admitted to the Department of Neurosurgery, Chinese PLA General Hospital from November 2015 to November 2016. There were 12 men and 7 women with a mean age of $63.57 \pm 9.17$ years (range, $46-79$ years). All the patients underwent conventional magnetic resonance imaging (MRI), including T1-weighted imaging (T1WI) and 3DASL (PLD = $2025 \mathrm{~ms}$ ). All the patients underwent CEA and were examined by MRI and 3D-ASL again on days $1,2,3$, and 4 and at 3 months after CEA.

\section{Inclusion and exclusion criteria}

The inclusion criteria were as follows: (1) The patient was diagnosed by DSA as having $\geq 70 \%$ unilateral carotid stenosis with a normal contralateral side; (2) Presence of neurological symptoms; (3) Absence of major organ dysfunction, tolerance to CEA, and no difficulty in exposing the stenotic segment; (4) The patient signed an informed consent form before the scans; and (5) Complete follow-up data were available.

The exclusion criteria were as follows: (1) Bilateral carotid stenosis or mild/moderate unilateral carotid stenosis; (2) Pregnant women and patients with contraindications for MRI, such as implantation of cardiac stents, pacemakers, or other metal objects; (3) Carotid stenting was used as the interventional therapy instead of CEA; (4) Presence of intracranial space-occupying lesions, large area of cerebral infarction, and other neurological diseases; and (5) Failure to measure the CBF due to unclear imaging.

\section{Scanning instruments, methods, and parameters}

A 3.0T scanner (GE Discovery MR750, GE Healthcare) with gradient strength of $50 \mathrm{mT} / \mathrm{m}$ and a 32-channel head surface coil was used for scanning. The patient was placed in a supine position in a quiet and relaxed state and scanned after his or her blood pressure reached a steady state. Image acquisition was performed after the blood pressure was maintained at a stable level as shown by the vital signs monitor in the MRI room. During each measurement, medical staff members were present in the MRI room to accompany and provide psychological counseling to the patient in order to stabilize his/her mood. Soft pads were used on Loading [MathJax]/jax/output/CommonHTML/jax.js 
both sides of the patient's head to prevent head movement, and earplugs were used to protect hearing. The 3D-ASL sequence parameters were as follows: Post-labeling delay (PLD), $2025 \mathrm{~ms}$; time repetition (TR), $4844 \mathrm{~ms}$; time echo (TE), $10.5 \mathrm{~ms}$; labeling interval, $1500 \mathrm{~ms}$; field of view (FOV), $240 \mathrm{~mm} \times 240 \mathrm{~mm}$; matrix, $512 \times 512$; number of excitations (NEX), 2; slice thickness, $4.0 \mathrm{~mm}$; scanning time, $281 \mathrm{~s}$; number of slices, 36 . In addition to the 3D pCASL images, a high-resolution volumetric T1W sequence was used to acquire anatomical images with the following parameters: TR, $7.1 \mathrm{msec}$; TE, $3.1 \mathrm{msec}$; bandwidth, $\pm 31.2 \mathrm{kHz}$; TI, 450 msec; slice thickness, $1 \mathrm{~mm}$; number of slices, 360; acquisition time, 4:43 minutes; FOV, $240 \mathrm{~mm}$; matrix, 256; and NEX, 1.

\section{Image processing and determination of CBF}

Original images of the scan sequences were transferred to an MRI image-processing workstation.

Pseudocolor images of CBF were generated using the image-processing software GE Function Tool (AW4.5, GE Healthcare). The image contrast was adjusted, and red, green, blue, and black colors represented a gradual decrease in perfusion. The frontal lobe, temporal lobe, watershed, and basal ganglia were selected as regions of interest (ROIs) for the measurement of $\mathrm{CBF}$. The $\mathrm{CBF}$ values of the contralateral areas were measured using images of the corresponding areas. The ROI was scanned within the same slice. All measurements were performed jointly by neurosurgeons and radiologists. Details are shown in Fig. 1.

\section{Statistical analysis}

Conventional MRI and 3D-ASL were performed on patients on the day before CEA; at $24 \mathrm{~h}, 48 \mathrm{~h}, 72 \mathrm{~h}, 96 \mathrm{~h}$, and 3 months after CEA. The CBF values of the lesion side and contralateral sides of the frontal lobe, temporal lobe, watershed area, and basal ganglia were expressed as

$x \pm s$. Theextentof $\in$ crease $\in$ perfusionpressurewascalcatedas $\left(\mathrm{x}_{\text {peak }}{ }^{-} \mathrm{x}_{\mathrm{pre}}\right) / \mathrm{x}_{\mathrm{pre}}$. Bilateral

differences were analyzed using the paired $t$ test. Comparison of preoperative and postoperative values was made using analysis of variance. Data of replicate measurements were analyzed using SPSS Statistics version 17.0. A P value of $<0.05$ was considered statistically significant.

\section{Abbreviations}

pCASL:pseudo-continuous arterial spin labeling;CEA:Carotid endarterectomy;CBF:Cerebral blood flow;CT:Computed tomography;DSA:Digital subtraction angiography;DSC:Dynamic susceptibility contrast;MRI:Magnetic resonance imaging;ROI:Regions of interest.

\section{Declarations}

Ethics approval and consent to participate

The study was approved by the Ethics Committee of the Chinese Peoples Liberation Army General Hospital , and written informed consent was obtained from all participants. 
Consent granted.

Availability of data and materials

The datasets used and/or analysed during the current study are available from the corresponding author on reasonable request.

Competing interests

The authors declare that they have no competing interests

Funding

None.

Authors' contributions

XG.Y., X.Z. and C.W.conceived and designed experiments. X.Z.and DS.K. performed the experiments. DS.K.and WX.W.analyzed the data.DS.K. wrote the paper.

\section{Acknowledgments}

We thank Ting Wang for the comments on neural data analysis, and Jinhao Lyu and Xiaoxiao Ma for data collection. We thank the reviewers/editors for critical reading of the manuscript. We appreciate the time and dedication of the patients and staff at Chinese PLA General Hospital, Beijing.

\section{References}

1.

Pizzini FB, Farace P, Manganotti P, Zoccatelli G, Bongiovanni LG, Golay X, Beltramello A, Osculati A, Bertini G, Fabene PF. Cerebral perfusion alterations in epileptic patients during peri-ictal and post-ictal phase: PASL vs DSC-MRI. Magn Reson Imaging. 2013;31:1001-5.

2.

Deibler AR, Pollock JM, Kraft RA, Tan H, Burdette JH, Maldjian JA. Arterial spin-labeling in routine clinical practice, part 2: hypoperfusion patterns. AJNR Am J Neuroradiol. 2008;29:1235-41.

3.

Noiphithak R, Liengudom A. Recent Update on Carotid Endarterectomy versus Carotid Artery Stenting. Cerebrovasc Dis. 2017;43:68-75.

4.

Mozzini C, Roscia G, Casadei A, Cominacini L. Searching the perfect ultrasonic classification in assessing carotid artery stenosis: comparison and remarks upon the existing ultrasound criteria. J Ultrasound. 2016;19:83-90.

5.

Sugino T, Mikami T, Miyata K, Suzuki K, Houkin K, Mikuni N. Arterial spin-labeling magnetic resonance Loading [MathJax]/jax/output/CommonHTML/jax.js 
6.

Pandya A, Gupta A. Improving imaging to optimize screening strategies for carotid artery stenosis. Clin Imaging. 2016;40:276-8.

7.

Lv P, Lin J, Guo D, Liu H, Tang X, Fu C, Hu J. Detection of carotid artery stenosis: a comparison between 2 unenhanced MRAs and dual-source CTA. AJNR Am J Neuroradiol. 2014;35:2360-5.

8.

Iwanaga T, Harada M, Kubo H, Funakoshi Y, Kunikane Y, Matsuda T. Operator-bias-free comparison of quantitative perfusion maps acquired with pulsed-continuous arterial spin labeling and single-photonemission computed tomography. Magn Reson Med Sci. 2014;13:239-49.

9.

Tanaka Y, Nagaoka T, Nair G, Ohno K, Duong TQ. Arterial spin labeling and dynamic susceptibility contrast CBF MRI in postischemic hyperperfusion, hypercapnia, and after mannitol injection. J Cereb Blood Flow Metab. 2011;31:1403-11.

10.

Zhang SX, Yao YH, Zhang S, Zhu WJ, Tang XY, Qin YY, Zhao LY, Liu CX, Zhu WZ. Comparative study of DSCPWI and 3D-ASL in ischemic stroke patients. J Huazhong Univ Sci Technolog Med Sci. 2015;35:923-7. 11.

Ances BM, McGarvey ML, Abrahams JM, Maldjian JA, Alsop DC, Zager EL, Detre JA. Continuous arterial spin labeled perfusion magnetic resonance imaging in patients before and after carotid endarterectomy. $J$ Neuroimaging. 2004;14:133-8.

12.

Yamamoto D, Hosoda K, Uchihashi Y, Fujita A, Sasayama T, Fujii M, Sugimura K, Kohta M, Kohmura E. Perioperative Changes in Cerebral Perfusion Territories Assessed by Arterial Spin Labeling Magnetic Resonance Imaging Are Associated with Postoperative Increases in Cerebral Blood Flow in Patients with Carotid Stenosis. World Neurosurg. 2017;102:477-86.

13.

Lan Y, Lyu J, Ma X, Ma L, Lou X. Longitudinal assessment of cerebral blood flow changes following carotid artery stenting and endarterectomy. Radiol Med. 2019;124:636-42.

14.

Wilson DA, Mocco J, D'Ambrosio AL, Komotar RJ, Zurica J, Kellner CP, Hahn DK, Connolly ES, Liu X, Imielinska C, Heyer EJ. Post-carotid endarterectomy neurocognitive decline is associated with cerebral blood flow asymmetry on post-operative magnetic resonance perfusion brain scans. Neurol Res. 2008;30:302-6. 15.

Oikawa K, Ogasawara K, Saito H, Yoshida K, Saura H, Sato Y, Terasaki K, Wada T, Kubo Y. Combined measurement of cerebral and cerebellar blood flow on preoperative brain perfusion SPECT imaging predicts development of new cerebral ischemic events after endarterectomy for symptomatic unilateral cervical carotid stenosis. Clin Nucl Med. 2013;38:957-61.

16.

Sato Y, Ogasawara K, Kuroda H, Suzuki T, Chida K, Fujiwara S, Aso K, Kobayashi M, Yoshida K, Terasaki K, Oqawa A. Preoperative central benzodiazepine receptor binding potential and cerebral blood flow images on Loading [MathJax]/jax/output/CommonHTML/jax.js 
SPECT predict development of new cerebral ischemic events and cerebral hyperperfusion after carotid endarterectomy. J Nucl Med. 2011;52:1400-7.

17.

Hosoda K. The Significance of Cerebral Hemodynamics Imaging in Carotid Endarterectomy: A Brief Review. Neurol Med Chir (Tokyo). 2015;55:782-8.

18.

Ogasawara K, Yamadate K, Kobayashi M, Endo H, Fukuda T, Yoshida K, Terasaki K, Inoue T, Ogawa A. Postoperative cerebral hyperperfusion associated with impaired cognitive function in patients undergoing carotid endarterectomy. J Neurosurg. 2005;102:38-44.

19.

Kirchoff-Torres KF, Bakradze E. Cerebral Hyperperfusion Syndrome After Carotid Revascularization and Acute Ischemic Stroke. Curr Pain Headache Rep. 2018;22:24.

20.

Ogasawara K, Sakai N, Kuroiwa T, Hosoda K, lihara K, Toyoda K, Sakai C, Nagata I, Ogawa A. Intracranial hemorrhage associated with cerebral hyperperfusion syndrome following carotid endarterectomy and carotid artery stenting: retrospective review of 4494 patients. J Neurosurg. 2007;107:1130-6.

21.

van Mook WN, Rennenberg RJ, Schurink GW, van Oostenbrugge RJ, Mess WH, Hofman PA, de Leeuw PW. Cerebral hyperperfusion syndrome. Lancet Neurol. 2005;4:877-88.

\section{Figures}
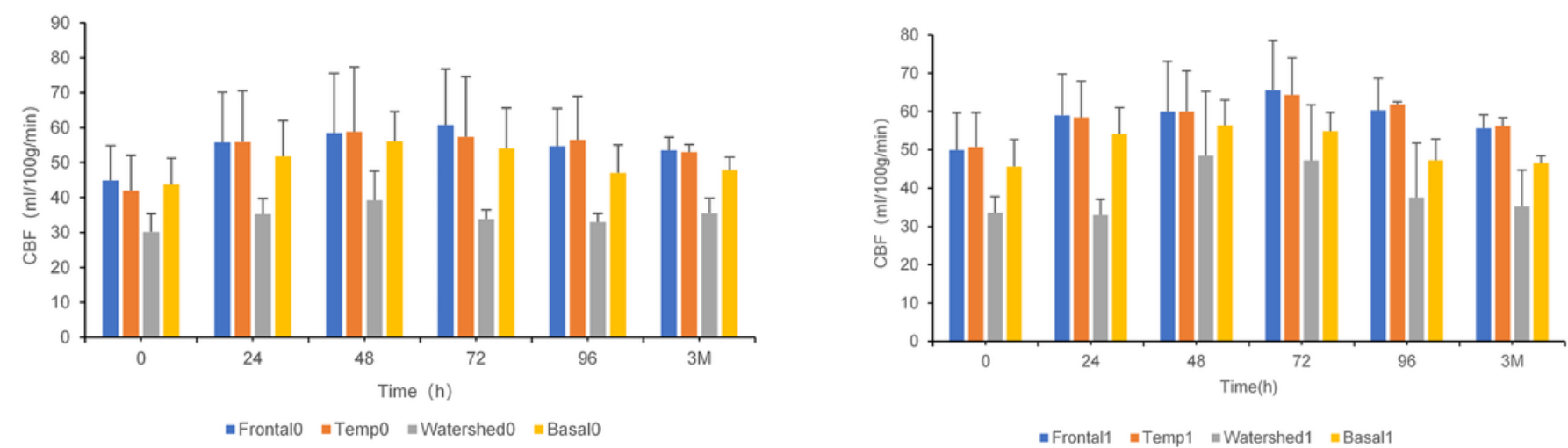

\section{Figure 1}

Perfusion trend of CBF for different regions on the ipsilateral side and the contralateral side.CBF values of the both sides showed a similar trend, while the contralateral side was smaller than that in the ipsilateral side. The frontal lobe and temporal lobe reached the peak on the ipsilateral side at $72 \mathrm{~h}$,the watershed area and basal ganglia in most patients reached the peak on the ipsilateral side at $48 \mathrm{~h}$.Data are expressed as mean \pm cटn 1 

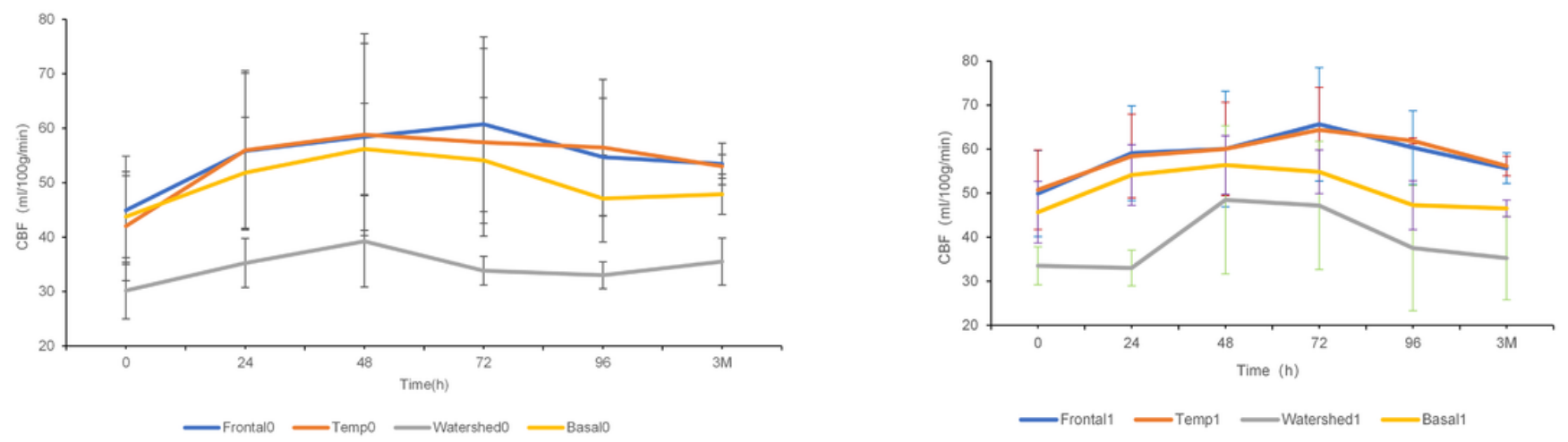

\section{Figure 2}

Mean CBF for different regions on the ipsilateral side and the contralateral side.The CBF values of the bilateral frontal lobe, temporal lobe, watershed area, and basal ganglia were increased after CEA ( $p<$ 0.01). There was a significant difference in CBF between the stenotic and contralateral frontal lobes $(p=$ $0.012)$, temporal lobe $(p=0.010)$, watershed area $(p \leq 0.05)$, and basal ganglia before CEA $(p>0.05)$, but the difference in CBF between the stenotic and contralateral frontal lobes was not significant after CEA ( $p$ > 0.05). Data are expressed as mean \pm SEM.

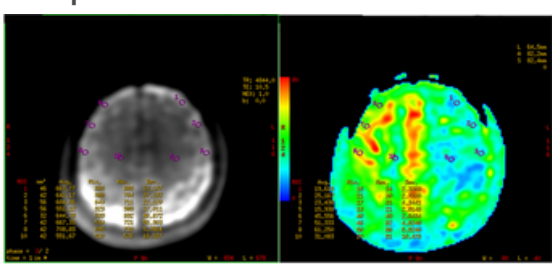

TO

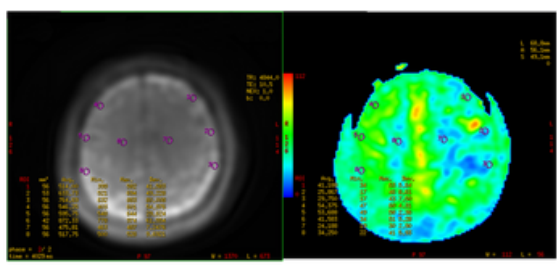

T3

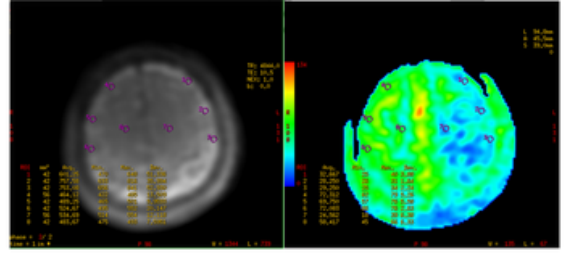

$\mathrm{T1}$

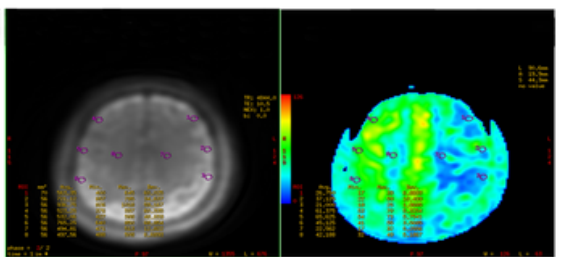

T4

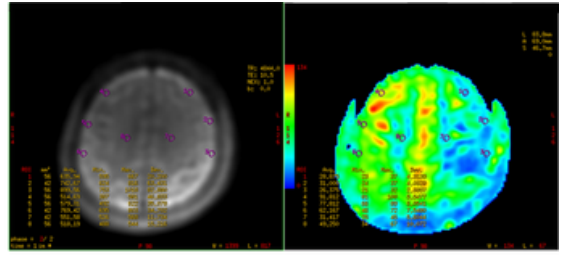

$\mathrm{T} 2$

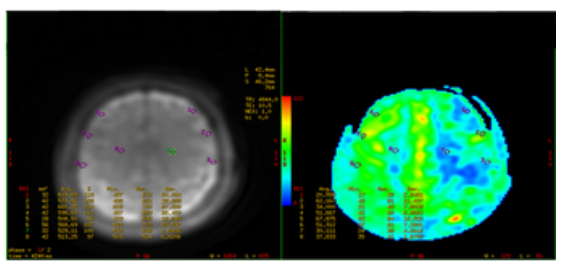

T3M

\section{Figure 3}

pCASL raw data images and CBF images. Red, green, blue, and black colors represented a gradual decrease in perfusion. The frontal lobe, temporal lobe, watershed, and basal ganglia were selected as ROls for the measurement of CBF. The CBF values of the contralateral areas were measured using images of the correspondina areas.ROls of white matter on 3D pCASL raw data images (left) and CBF images (right). T0, Loading [MathJax]/jax/output/CommonHTML/jax.js 
before operation; $\mathrm{T} 1,24 \mathrm{~h}$ after operation; $\mathrm{T} 2,48 \mathrm{~h}$ after operation; $\mathrm{T} 3,72 \mathrm{~h}$ after operation; $\mathrm{T} 4,96 \mathrm{~h}$ after operation; T3M, 3months after operation. 